\title{
For great development in pharmacology and clinical science: With fruitful navigation of "Integrative Pharmacology and Clinical Science"
}

\section{Yasuyuki Nomura*}

Department of Pharmacology in School of Medicine, Kurume University, Japan

\section{Welcome message}

It is really our pleasure to ascertain the inauguration of Integrative Pharmacology and Clinical Science (IPCS). We believe the IPCS should play important roles in the promotion in a link between basic life sciences and clinical science, resulting in application to pharmacological manipulation in clinical therapy.

Pharmacology seems to include a variety of target field and methodology. Therefore, novel findings by the active research works tend to diverse one another. The close communication could be essential for the development of basic and clinical pharmacology. Every field of pharmacology should closely communicate, exchange up-todate information and encourage one another. IPCS will undoubtfully play an inevitable contribution.

Sciences rapidly progress nowadays, and novel findings accumulate day by day. Novel achievements should be disclosed and widely disclosed to every scientist at an early opportunity. Original results, concepts and new methodology will lead to innovation of new medical development and happiness of mankind.

We expect and request all readers to submit excellent manuscripts and contribute to scientific development and human happiness.
Copyright: (C2018 Nomura Y. This is an open-access article distributed under the terms of the Creative Commons Attribution License, which permits unrestricted use, distribution, and reproduction in any medium, provided the original author and source are credited.
*Correspondence to: Yasuyuki Nomura, Department of Pharmacology in School of Medicine, Kurume University, Japan, E-mail: nomura_yasuyuki@kurume-u.ac.jp

Received: November 26, 2018; Accepted: November 30 2018; Published: December 03, 2018 